\title{
TÉCNICA DIALÉTICA E EIDOS ALGUMAS CONSIDERAÇÕES PARA REFLEXÃO SOBRE DIALÉTICA DE PLATÃO
}

Rachel Gazolla*

SÍNTESE - A dialética em Platão é, por um lado, uma técnica que planta e semeia as "sementes do logos"; ela é, então, algo que pode ser ensinado e aprendido na relação Mestre e Discípulo. Por outro iado, Dialética é uma episteme, através da qual é possivel contemplar o ser e o inteligível; ela é um saber mais perfieito e pertence, não ao âmbito da técnica, do poieîn, mas ao domínio do contemplar, do theoreîn. Dialética neste segundo sentido trabalha, primeiro, com hipóteses, para depois conduzir à visão noética, na qual ela consegue ver seus fundamentos.

PALAVRAS-CHAVE - Dialética, Platão, técnica, contemplação.
ABSTRACT - To dialectic in Plato is, on one side, a technique that plants and it sows the "seeds of the logos"; she is, then, something that can be taught and learned in the relationship Master and Pupil. On the other hand, Dialectic is a episteme, trrough which is possible to contemplate being and the intelligible; she is a more perfect krowledge and it belongs, not to the ambit of the technique, of the poiein, but to the domain of contemplatirg, of the theorein. Diaiectic in this second sense works, first, with hypotheses, for later to drive to the vision (noiésys), in which she gets to see its foundations.

KEY WORDS - Dialectic, Plato, technique, contemplation.

“Tu tens bem fluente língua como quem pensa (phronôn), mas pensamento (phrénes) não te assiste nos dizeres (en toîs lógoisi)..." (Euripides, Baccantes, v. 268)

Inicialmente, cito a República quando Platão faz Sócrates dialogar com Glałke (537 e) nos seguintes termos:

S - "[...] nâo notaste, pergunto, o mal que alcançou hoje o dialogar (tó dialégesthai) e o que veio a ser?

G-Qual?

$S$ - Está completo de desordem (paranomías), respondi.

G-E muito..."

* Doutora em História da Filosofia Antiga pela Universidade de São Paulo - USP e Professora Titular da Pontificia Universidade Católica de São Paulo PuCsP. Esta palestra foi proferida no I Congresso Internacional de Dialética - Porto Alegre, RS - Maio/1998.

\begin{tabular}{|l|l|l|l|l|l|}
\hline VERITAS & Porto Alegre & v. 43 & $n^{0} 4$ & Dezembro 1998 & p. 961-968 \\
\hline
\end{tabular}


Com fácil concordância de Glauco, sabemos que não há grande surpresa quanto ao dialogar estar pleno de "paranomías", à época. Após tal afirmativa, Platão utiliza-se do exemplo de uma criança criada por pais adotivos, que fica sabendo só mais tarde de sua adoção, e se confundirá com tal fato diante de si e dos outros em função de uma situação para ela inesperada. Compara a vivência desssa criança com as da aima humana, pois são necessárias certas precauções para que ambas, a criança e nossa alma, nấo confuñam sua própria identidade diante de circunstâncias imprevisiveis.

A comparação pretende servir para o caso daqueles que devem aprender a dialética, pois é fundamental que já tenham a alma moderada e firme para poderem bem servir-se dela. Diante disso, Glauco quer saber em que exemplo da criança adotada pode aproximar-se do dialético que se quer formar na cidade justa. E Sócrates responde:

“[...] Temos desde a infância, sobre a justiça e a beleza, máximas (dógmata) dos pais que nos formaram e que temos 0 hábito de seguir e respeitar [...] Há outras opostas a essas, máximas prazerosas que seduzem nossa alma e lançam-na a elas [...] Quando não se puder mais reconhecer o valor dessas coisas e seu parentesco com a alma, e de outro lado não se encontrar mais o que é preciso acreditar, como conduzir-se normalmente senão para aquelas que seduzem?"

Inicio minha fala com tais citações, porque gostaria de indicar dois pontos importantes que ajudam a compreender o que é a dialética platônica: a facilidade com que Glauco aceita que o modo de dialogar à época é um "kakós", e a relação que Platão estabelece entre a natureza da alma e a dialética. Portanto, deve-se perguntar que tipo de dialogar o filósofo está preocupado em criticar e o que ele mesmo tem a propor. Na segunda citação, ao comparar os valores paradigmáticos nos quais somos formados desde a infância, com os outros valores de cunho prazeroso, aprendidos na vivência dos costumes, Platão adverte que, se não reconhecermos o valor das coisas em seu parentesco com a alma, acolheremos as que nos seduzem por serem aparentemente prazerosas.

-... Essa questão é especificamente espinhosa e não vou tratá-la aqui por referirse à problemática do prazer e dor, desenvolvido no Philebo. Fica, entretanto, a questão do parentesco da alma com o que recebe como princípio e solo para a conduta diante de uma situação eventual de vazio de princípios e que, como adverte Platão, pode ser preenchida sedutoramente.

Parece clara a referência platônica aos lógoi ${ }^{1}$ sedutores dos sofistas de sua época e à vivência -das leis e julgamentos da cidade, mutáveis tanto quanto a perșluasão dos cidadãos diante das palavras dos oradores. Quando a alma está no vazio de valores, parece dizer Platão, a retórica como arte de bem falar e calar no momento oportuno pode preencher tal vazio. As belas palavras que os oradores criám para seduzir indicam que o lógos é plástico, amolda-se ao processar técnico e tem como objetivo sua própria glória. A persuasão cria, com facilidade, muitos valores naqueles que estão sem parađigmas. Há uma "psychagôgia", como Platão nomeia no Fedro (271 d), no exercício da potência do lógos, que pode levar as almas para onde quer 0 orador.

1 Não traduzirei a palavra lógos pois sua conotação é extensa: razão em sentido mais amplo do que a modernidade considera, discurso, argumento, palavra, reflexão, julgamento. 
Nesse diálogo, o filósofo aponta para a necessidade de pensar a parentesco entre a alma e o lógos. Diz que, assim como existe uma natureza da alma, também haverá uma natureza do lógos, e é preciso as duas para saber da aitia, da causa, isto é, daquilo pelo que há a produção da persuasão de um lado, e da nãopersuasão, de outro (ech anánkés hé mén peíthetai, hé đè ápeítheí), (271 b).

Que força é essa que, em se usando o mesmo 'material', o lógos no caso, é possivel produzir efeitos diversos, persuadir ou não-persuadir? É essa a pergunta e uso nucleares da Sofística. Deve-se perguntar, também, se Platão consegue persuadir quando faz filosofia na forma dialógica, tanto quanto os demais oradores. Em que sua dialética se diferenciaria dos argumentos sofísticos na arte de persuadir por palavras? Não é a dialética uma forma de persuasão como o são os dissói lógoi acompanhados da arte da retórica?

A dialética é definida, ainda no Fedro, como uma técnica que, levando pela mão a alma, planta e semeia epistêmés lógous (277 a). Esse modo de lógos estruturar-se consegue ser uma doação tanto àquele que planta quanto ao que recebe $o$ plantio, de forma a produzir em quem o recebe novos lógoi, usando da mesma matéria, como aprendeu. A dialética é, então, uma técnica e é ensinável.

Todavia, no livio VI da República (511 c), diz ele que o dialogar é uma epistême através da qual é possivel contemplar o ser e o inteligivel (tés toû dialégesthai epistêmés toû óntos te kaí noêtoû theoroúmenon). Enquanto technê, ela produz algo que não existia, pois é essa a definição de técnica, no Sofista. Está no dominio do fazer como poieîn, fabricar. Enquanto epistême, a dialética estrutura-se como um saber mais perfeito, pertinente ao domínio do theorein, do contemplar. Como téchnê, ela assim o é de modo sui generis, na medida em que nem sempre segue os procedimentos e fins das técnicas gerais, quais sejam, o de produzir algo para o uso, produzir tá chrêmatá, coisas utilizáveis que têm um valor.

Ao produzir um sapato, por exemplo, o sapateiro pode ensinar a alguém as etapas do processo para tal produção, sem que tal ensinamento seja para ele um aprendizado, pois sendo sapateiro tem já a posse desse saber. O produto - o sapato - e o processo de fazê-lo não são imanentes à relação sapateiro-aprendiz, 'e este terá que exercitar-se muito até que produza, pelas etapas ensinadas pelo mestre, um bom sapato, sem necessariamente usá-lo. Não deixa de haver, entrẹtanto, uma semelhança com o processo dialético como técnica. Como processo técnico, tanto o sapato quanto um diálogo são ensináveis e produzem algo átit Talvez por isso, Sócrates tenha visto alguma sabedoria nos artesãos (Apologia):

Também o médico, sendo um técnico, produzirá o remédio certo para o doente específico, mas ele mesmo não está imanente ao processo do produto, e o doente, não dependendo de receber ensinamentos sobre a arte médica, está lígado ao produto final, o remédio, enquanto que o médico, não.

O que há de sui generis no dialogar como técnica? Aquele que usa tal matéria, o lógos, poderá ou não estar imanente ao processo e ser a causa que produza tal lógos, ser sua causa eficiente, seu produtor. No caso da técnica dialética como quer pensá-la Platão, coloca-se ela como semeadura e plantio. Tal postura implica na imanência de mestre e điscípulo no ensinar e aprender. Em termos causais, há imanência entre aquele que produz e o que recebe o produto. Mas, sabemos que 
um diálogo não é, necessariamente, sempre assim. Ao utilizar-se do lógos como força de domínio do outro pela persuasão, um procedimento que pressupõe a guerra dos argumentos e a violência com a disposição das palavras para preenchimento do vazio do outro, estaremos dentro do processo técnico próprio aos sofistas e à esfera jurídica. Tem-se em vista, nesse caso, um determinado fim útil: a persuasão dos ouvintes. Estes são colocados passivamente no processo dialógico, como o sapateiro e seu aprendiz.

Nessa configuração, o diálogo é uma técnica como outra qualquer, no sentido de que produzir algo antes inexistente que passa a ser e é útil. Ao invés de produzir sapatos ou a cura do doente, processam-se argumentos plenos de valores para criar novas opiniões no ouvinte.

O momento em que, no Fedro, Sócrates afirma a dialética como técnica, parece-me que está indicando que seu processo não é esse, uma vez que tanto o que ensina como o que aprende o dialogar ganham, mutuamente, ensinamento. É exatamente esse um dos pontos nevrálgicos - já que há outros - que afastam o Platão técnico-dialético do sentido de técnica usualmente compreendida à época. Sem dúvida, o processo técnico implica sempre em violência, qualquer que seja seu tipo, na medida em que destrói e reconstrói a matéria sobre a qual trabalha (amplo sensu) imprimindo-lhe a forma que se queira em direção a um fim. Como pensar o processo técnico sem a violência que lhe é concernente?

Ora, o dialogar platônico enquanto técnica tem seu aspecto violento, destruidor e construtor. Afinal, já a maiêutica socrática tinha essa tônica, bem sinalizađa na ironia. Porém, de mođo fundamentalmente diferente dos dissói lógoi dos sofistas e dos oradores dos tribunais, o processo dialético platônico mantém os dialogantes em consonância, mais que isso, em philía. Essa é a pedra de toque que transforma toda a perspectiva do pensamento técnico em Platão, não só com referência à dialética.

Como epistême, na República, ela é um caminho para, ou seja, um método que leva a alma ao conhecimento das idéias, como o filósofo expiicita ao final do livro VI. Assim sendo, é importante que sejam mantidos dois ângulos para pensar a dialética platônica: como technê e como epistême. A técnica pressupõe o lógos enquanto potência capaz de criar novos lógoi - e nessa acepção o processo tem cunho genético, de nascimento. Enquanto ciência, pressupõe-se o lógos no seu poder mais amplo de pensar as idéias e ensiná-las como fundamento das sentenças bem dispostas ou doxai.

É possível dialogar sem ensinar o outro. Pode-se simplesmente aprender as idéias para si mesmo, circularmente, efetivando a semeadura e o plantio de uma só vez, como se houvesse um 'eu' e um 'outro' de si mesmo. Efetivamente, Platão define o lógos do seguinte modo, no Sofista (263 e, 264 a):

“[...] Reftexão (diánoia) e discurso (lógos) é o mesmo, salvo que é o diálogo e silencioso da alma consigo mesma a que damos o nome de reflexão (diánoia).

[...] Mas a corrente que emana da alma e sai pela boca na emissão vocal recebeu o nome de discurso (lógos)?

[...] Sabemos que há, ademais, discursos (lógois) [...] que afirmam e negam [...]

[...] Quando, então, isto se faz na alma, segundo a reflexão (diánoia), silenciosamente, tens outra palavra para designá-lo senão opinião (dóxa) [...]?" 
Dizer e refletir (lógos), portanto, são nomeados diversamente na linguagem comum e estão referidos a uma técnica que pode ser ensinada e a uma ciência a que alguns podem alcançar. Se dizer é o mesmo que refletir e opinar, quando julgamos ou opinamos sobre algo, de modo a afirmar ou hegar esse algo sentencialmente, o princípio é o mesmo: é o lógos exprimindo-se dessa ou daquela forma. Se dialogamos com a alma, interiormente, sem ensinar o outro mas a nós mesmos, plantamos e semeamos o próprio solo e alcançamos, como o sapateiro antes de fabricar o sapato, aquilo de que precisamos para chegar a um fim e que já está no início: no caso do sapateiro, a forma (eidos) do sapato a ser produzido; no caso do técnico-dialético a clareza dos princípios que fundarão suas sentenças, as idéias (um outro modo de pensar eidos). Afinal, se a filosofia pretende demonstrar os fundamentos do sapateiro - o que ele não pode demonstrar - tem que saber de seus próprios fundamentos.

Como se houvesse um redobro da matéria, da forma, do fabricador e do seu fim, assim é que o processo de produção 'lógico' está sendo construído. É a matéria e forma que impulsionam a demiurgia. Todavia, há uma quebra da circularidade no processo técnico dito não noético, conforme o livro VI da República. Quebra-se o círculo quando entre o homem que fabrica e o produto fabricado há um terceiro: aquele que receberá o produto e que não está envolvido no processo. Parece ser esse um ponto importante para compreender o pensamento técnico em Platão e sua crítica parcial às técnicas, pois a dignidade do ser humano, exercitando-se circularmente com objetos, pode impedir o desenvolvimento de sua alma. É sua crítica clara no Górgias, que não abordo nesse contexto.

Essa quebra não ocorre na dialética, pois sua forma e sua matéria são o próprio lógos na sua potência de ir e vir do sensivel ao inteligivel, construindo o movimento dia-noético. Nesse ponto está, também, a grande diferença entre as technai fabricadoras de objetos e aquelas que trabalham com hipóteses, como as matemáticas e técnicas afins. Nesse sentido que a própria dialética é uma técnica, como o é a matemática. Diz Platão na República (511 b, c, d):

S - "[...] Aprende então o que quero dizer com o outro segmento do inteligivel (toú noétou), daquele que o lógos atinge pela potência do dialogar (dialégesthai dynámei), fazendo das hipóteses não principios mas hipóteses realmente [...]até chegar à conclusắo, sem servir-se de nenhum sensivel (aisthétô) [...]

G - "Compreendo [...] queres determinar que é mais claro a contemplação do ser e do inteligivel pela ciência do dialogar (tou dialégesthai epistêmes tou ontos te kai noêtou theôroúmenon) do que pelas nomeadas technai cujos princípios são hipóteses [...]".

Como epistême dialética, como esclarece Platão, leva a alma ao ser e ao nous, e a técnica dialética, como as outras técnicas, é exercitada no decorrer desse processo para, primeiramente, trabalhar com hipóteses e, depois, ter a visão noética. Desse modo, a circularidade do lógos na alîna"move-se para algo e encontra, aí mesmo, seus próprios fundamentos, à diferença da circularidade técnica que permanece nos objetos ou nas hipóteses.

É essa circularidade que Platão quer resgatar integralmente para o ensinar filosófico. A bem dizer, a técnica dialética no sentido platônico necessita da ciência dialética para processar-se, mas o discípulo só saberá disso ao final de seu movimento. Só então poderá 'ver' seus fundamentos. 
Parece-me que o diálogo platônico - que quer a imanência ou o parentesco do mestre e discípulo na matéria em que trabalham (o lógos) - preserva tal parentesco na medida mesma das dynameis da alma de cada um. O logistikón, ou a forma logística da alma, deve estar em consonância no mestre e no discípulo para o exercício dialético, e nem todos os homens apresentam forte propensão ao uso dessa potência da alma. Porém, só esse eidós da alma é capaz de compreender a si mesma no seu movimento, princípios e limites.

Assim sendo, a técnica do lógos necessariamente é ultrapassada no seu processar-se para tornar-se ciência quando, então, pode saber-se enquanto poder técnico. O que faz a especificidade da técnica dialógica é o fato de o dialético impor, a priori, o afastamento das "paranomias", isto é, da carência de um produzir que não sabe de si mesmo. Aquele que ensina o outro ou a si mesmo - isto é, que faz o plantio em seu próprio campo ou no campo alheio - deve ter a posse de certos paradigmas que norteiem os laços de parentesco da alma com os seres e os dizeres. São tais paradigmas esses fundamentos que, no caso do dialético-mestre, são adquiridos na contemplação das idéias, antes de ensinar.

Agora, já podemos voltar à citação inicial da República: assim como as dógmața ensinadas pelos pais têm parentesco com a formação da alma e dos valores das ações futuras, também as idéias são os paradigmas que têm parentesco com a alma e seu saber mais perfeito. O discípulo saberá disto ao final do processo. O mestre já o sabe antes. Essse caminho que pressupõe paradigmas no seu início e no seu fim aponta para a busca do que já se sabe e de seu reconhecimento ao final, que é, a rigor, um reencontro, conforme Platão anuncia no Ménon, ao expor o lógos da reminiscênciá. Não se pode ensinar se não se sabe, a priori, os fundamentos do que se ensina.

Todavia, qual é o fio condutor do mestre que, sabendo mais, não exerce 0 mesmo tipo de técnica persuasiva e de força dos debates jurídicos e sofísticos? t́ preciso compreender o que é o átomon eidos, pois é esse o fio que o mestre não pode perder nos seus argumentos ao discipulo. É isso que cria os laços de koinonía entre eles.

O que está no começo e no fim, as idéias, deslizam no proceder dialético como busca invisivel do átomón eidos, ou seja, da forma indivisível, una e final do ser que se pesquisa, quer seja ele o pescador com o anzol, no Sofista, quer seja a Justiça, na cidade justa. O que é átomon eidos?

H. G. Gadamer, em seu livro A ética dialética de Platão", ${ }^{2}$ considera, com grande sensibilidade, que o trabalho dialético da diaíresis - a divisão do tema proposto em partes - baseia-se, verdadeiramente, em descobrir unidades novas até tocar o limite, que é o átomon eidos (o que, nạ matemática é o ponto). Sabemos que o diálogo $O$ Político é um bom exempló disso. Decomposto um tema submetido ao filósofo, inicia-se a busca da unificağa a através da divisão, trabalho antinômico tão ao gosto de Platão. Destrói-se para construir, divide-se para unir. Tem-se como guia a forma última, o não divisível. Diz Gadamer:

2 Léthique dialectique de Platon, ed. Actes Sud (trad. do alemão Platos dialektische Ethik, Verlag). 
"[...] buscando alcançar um último 'eidos' indivisivel, que resume a coisa em sua irredutivel unidade, tem-se, dessa vez, a certeża de ter alcançado o ente em questão, ele e não um outro, em um lógos que fixa, de uma vez por todas, seu ser idêntico a si [...] graças à especificação, o ente é concebido segundo a permanência de sua natureza. Este método de definição por divisões sucessivas encontra seu arquétipo na determinação numeral, assim como Sócrates mostrou-se tomando como exemplo a teoria musical"' (p. 185).

Parte-se, portanto, da empiria múltipla. Por exemplo, no Banquete, a pergunta sobre o que é o amor apresenta-se, primeiramente, na variedade de opiniões a respeito; ou no Ménon, a pergunta sobre o que é a virtude inicia-se com diversas opiniões já assentadas. Toma-se nas mãos um fio condutor para a unidade - o que é o amor ele mesmo? O que é a virtude ela mesma? fio que não está mergulliado na sedução prazerosa de certos lógoi, ao contrário, necessita da firmeza, moderação e disposição da alma daquele que pergunta, tendo em vista a dificuldade desse exercitar-se, dessa áskesis profundamente amorosa.

O Eros dialético explicita-se no modo como o diálogo flui ou ele mesmo é o Eros, nas suas regras, interrupções, silêncios, mudanças de rumos, volteios, nas astuciosas metáforas, alegorias, exemplos, no uso de mitos, no drama, naquilo tudo que o lógos, na sua plasticidade, dá a conhecer. Enfim, como díz Platão no Fédon, o diálogo - ou o lógos como diálogo - é um exercício que afasta a alma do corpo, enquanto esta se exercita para alcançar as realidades inteligiveis. "Dialogar é, portanto, mais que tangencial à definição da própria Filosofia, é sua essência, é a própria exposição do Eros como um daimôn" (cf. Banquete).

Quando se trata do diálogo com o outro, então é preciso que todo o caminho seja construído em koinonía mútua para que não se arvore o mestre-dialogante em senhor do lógos. Mesmo quando ao ler os diálogos, ficamos com a impressão de que o discípulo apenas confirma o dizer do mestre, é um simples 'marionete', não é assim. Aquele que ensina tem em mãos, sim, o fio condutor, ou seja, o saber dos paradigmas que norteia, na muitiplicidade, a procura do átomon eidos. Ele tem parte do aríthmos do diálogo, parte de seu fluxo, mas não pode ir adiante sem que o discípulo acompanhe, passo a passo, o movimento do que se está expondo.

O mestre depende da firme anuência por parte daquele que ouve, de que aquilo que está sendo expresso, que está sendo pensado e falado, está sendo incorporado no discípulo, vivenciado do mesmo modo como o expositor o está pensando. ${ }^{3}$ Essa é a temporalidade do dialogar. Daị a importância da koinonía na filosofia de Platão: comunidade das idéias, comunidade do lógos, comunidade na cidade justa, comunidade na demiurgia (entre o produtor e o produto), comunidade da aima e do corpo.

Essa progressão, esse arithmós do diálogo implica, como nota ainda Gadamer, ${ }^{4} \mathrm{em}$ conhẹecer o número (tradução assentada de arithmós), em dominar uma técnica, lembrando o Górgias (501 a, 8) e o Fedro (270 d, 6 e, 273 e, 1). Dominar

3 Não me pargede possivel supor que haja, em função dessa postura, uma 'intersubjetividade'. Não se póde esquecer que o lógos é recolhido pelos homens e a eles fala e se dá a pensar segundo o próprio modo de ser humano. Vários fragmentos de Heráclito demonstram esse sentido e Platão não rompe com tal tradição. É preciso cuidado, porém, para não considerar o lógos transcendente ao mundo ou, ao inverso, considerá-lo cartesiamente como razão.

4 Op. cit. p. 187. 
uma técnica é poder justificar suas etapas, o que só é dispensável para uma saber que não conheça a natureza do que faz e que Platão nomeia rotina, diferenciando da técnica que conhece suas etapas apesar de não conhecer seus fundamentos. São as palavras de Sócrates, no Górgias, ao diferenciar a cozinha como saber rotineiro e a medicina como saber técnico.

Para Gadamer, a dialética enquanto saber técnico reporta-se à diversidade das coisas sensiveis divididas em gêneros e espécies, de modo a poder chegar ao "quid" da coisa, à ousía. Dito com outras palavras, poder chegar ao limite do próprio lógos até que ele ofereça o ser da coisa na sua permanência. Isto será seu átomon eidos. Não deixa de ser uma forma de violência.

Lembrando a citação inicial que fiz da República, e relacionando-a com as colocações de Gadamer, creio que ele tem toda a razão na sua leitura.

Ao finalizar, quero supor que essa "função técnica" da dialética seja transcendida no próprio exercitar-se lógico. Isso porque, encontrar a forma última, o átomon eidos, é, de uma só vez, encontrar o princípio que, silenciosamente, norteava a procura. O fim está no começo, o que significa dizer que já se estava de posse da epistême quando se iniciou o ensinamento da técnica que, nada mais é, nèsse sentido, que reminiscência. Uma violência, sim, como disse, pois é parturição do que se carregava. Daí ser o filósofo um parteiro que domina a técnica e o fundamento da parturição, pois tem o conhecimento que Platão denominou, ao final do livro VI da República (511 b), de inteligivel (noéton).

A dialética (ou o dialogar) apresenta-se, portanto, como uma arte do lógos, uma "dynamis" que ele possui e que oferece uma outra face de si mesmo dada sua plasticidade: pode ser também o veículo da e para a epistême. 